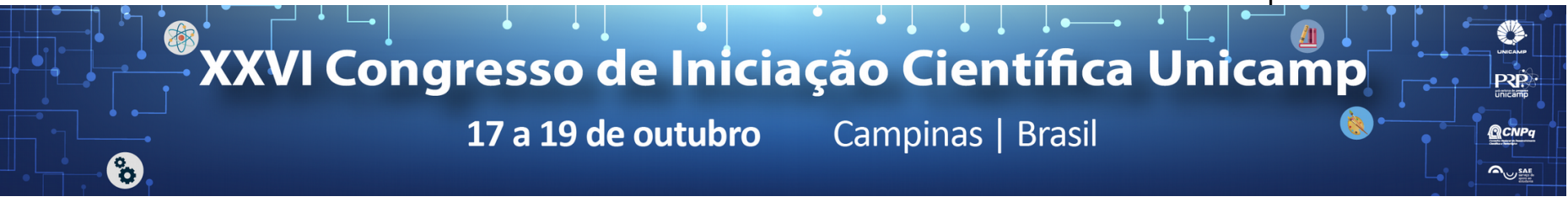

\title{
Produção de Filmes de ZnO por ALD (Atomic Layer Deposition)
}

\author{
Thiago Francisco Clementino De Oliveira*, Francisco das Chagas Marques
}

\section{Resumo}

Filmes finos de ZnO tem várias aplicações em dispositivos eletrônicos como em diodos, transistores, dispositivos piezoelétricos e células solares. Neste trabalho desenvolvemos este material pela técnica ALD (Atomic Layer Deposition) utilizando um equipamento recém adquirido pelo laboratório de pesquisas fotovoltaicas do IFGW. Esta técnica permite deposições camada-por-camada (layer-by-layer) dos filmes de maneira conformal (o filme se deposita assumindo a forma da superfície do substrato). Investigaremos o efeito da temperatura entre $100^{\circ} \mathrm{C}$ e $300^{\circ} \mathrm{C}$.

\section{Palavras-chave:}

Deposição, Semicondutores, Filmes Finos.

\section{Introdução}

Compreender que estamos num estágio de tecnologia e ciência onde materiais cada vez menores são imprescindíveis na indústria e na academia, para diversos fins, como, por exemplo, o uso de dispositivos semicondutores em smartphones na indústria, nos faz olhar com outros olhos para esse tipo de deposição, que vem sendo cada vez mais utilizado, dado o controle atômico que é possível atingir.

O ZnO é um semicondutor com uma alta energia de banda proibida, 3,37 eV, a temperatura ambiente, e com sua alta transparência a luz visível e condutividade elétrica tunelável, se torna aplicável em células solares e dispositivos optoeletrônicos, como LEDs e fotodetectores, já que possui propriedades piezoelétricas, por exemplo. Além disso, este material se cristaliza na estrutura hexagonal wurtzite (Figura 1), e tem condutividade intrinsecamente do tipo-n, dificultando a obtenção de filmes com condutividade do tipo-p, tornando um desafio a aplicação deste material em junções pn.
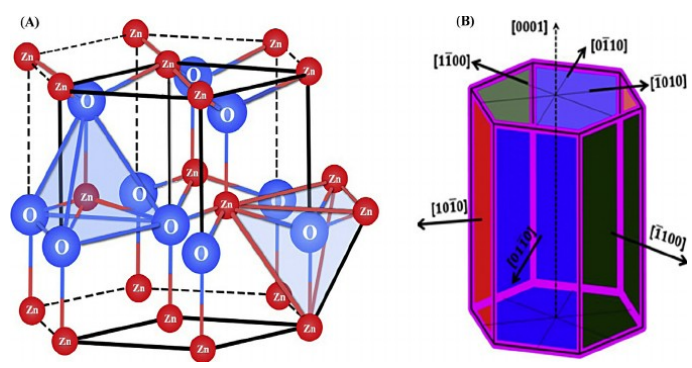

Figura 1. Estrutura hexagonal wurtzite do $\mathrm{ZnO}$.

As reações são sequenciais camada-por-camada (layerby-layer), onde cada camada tem a dimensão de uma monocamada do material. Além disso, a deposição é conformal, ou seja, o filme se deposita sobre a superfície do substrato independente de sua forma, ou seja, recobrindo toda a superfície do substrato, plano ou irregular. A deposição se dá de forma sequencial.

\section{Resultados e Discussão}

Após compreender como se dá a deposição, o estudo foi dirigido para as variáveis de controle de cada processo, sempre relacionando-as com as características dos filmes de ZnO obtidos através delas.

As variáveis de controle mais importantes na produção desse filme utilizando ALD são os precursores utilizados no processo. Os mais utilizados hoje são DEZn, o dietilzinco, e a água, com temperaturas de deposição entre $100^{\circ} \mathrm{C}$ e $200^{\circ} \mathrm{C}$. Na tabela 1 estão especificadas diversas deposições com suas variáveis.

\begin{tabular}{|c|c|c|c|c|c|c|}
\hline Nome & Substrato & Temperatura ( ${ }^{\circ} \mathrm{C}$ ) & $\mathrm{T}_{1}(\mathrm{~s})$ & $\mathrm{T}_{2}(\mathrm{~s})$ & $T_{3}(s)$ & $\mathrm{T}_{4}(\mathrm{~s})$ \\
\hline Zno-001 & $\mathrm{Si}(100)$ & 150 & 0,15 & 0,15 & 0,50 & 0,75 \\
\hline $\mathrm{ZnO}-002$ & Si (111) & 150 & 0,15 & 0,15 & 0,50 & 0,75 \\
\hline Zno-003 & Si $(100)$ & 150 & 0,15 & 0,15 & 10,00 & 20,00 \\
\hline Zno-004 & $\mathrm{Al}_{2} \mathrm{O}_{3}$ & 150 & 0,15 & 0,15 & 10,00 & 20,00 \\
\hline Zno-005 & Vidro & 150 & 0,15 & 0,15 & 10,00 & 20,00 \\
\hline ZnO-006 & Ge & 150 & 0,15 & 0,15 & 10,00 & 20,00 \\
\hline ZnO-007 & $\mathrm{Al}_{2} \mathrm{O}_{3}$ & 150 & 0,15 & 0,15 & 10,00 & 20,00 \\
\hline ZnO-008 & Si (111) & 150 & 0,15 & 0,15 & 10,00 & 20,00 \\
\hline ZnO-009 & $\mathrm{Al}_{2} \mathrm{O}_{3}$ & 180 & 0,15 & 0,15 & 10,00 & 20,00 \\
\hline $\mathrm{ZnO}-010$ & $\mathrm{Si}(111)$ & 180 & 0,15 & 0,15 & 10,00 & 20,00 \\
\hline ZnO-011 & $\mathrm{Al}_{2} \mathrm{O}_{3}$ & 210 & 0,15 & 0,15 & 10,00 & 20,00 \\
\hline ZnO-012 & $\mathrm{Si}(111)$ & 210 & 0,15 & 0,15 & 10,00 & 20,00 \\
\hline Zno-013 & $\mathrm{Al}_{2} \mathrm{O}_{3}$ & 240 & 0,15 & 0,15 & 10,00 & 20,00 \\
\hline ZnO-014 & $\mathrm{Si}(111)$ & 240 & 0,15 & 0,15 & 10,00 & 20,00 \\
\hline
\end{tabular}

Tabela 1. Diferentes filmes depositados, sobre diferentes substratos, com os tempos de pulso e purga de cada precursor.

\section{Conclusão}

Foi possível relacionar diversos conhecimentos aprendidos durante o curso de Física com o que foi visto nos artigos de referência, além de estudar uma técnica diferente e estudar um material que pode cumprir um papel muito importante no futuro. 